\title{
High iso aldehyde selectivity in the hydroformylation of short- chain alkenes
}

\author{
Leo lu, ${ }^{[a]}$ José A. Fuentes, ${ }^{[a]}$ Mesfin E. Janka ${ }^{[b]}$ Kevin J. Fontenot ${ }^{[b]}$ Matthew L. Clarke ${ }^{\star[a]}$
}

\begin{abstract}
The hydroformylation of propene to give predominantly iso-butanal has been achieved; class-leading selectivity is possible even at higher temperatures that deliver fast rates. Racemic Rh complexes of bidentate phospholane phosphites derived from tropos-biphenols and unusual solvent systems are the key to the selectivity observed.
\end{abstract}

Rh-catalysed hydroformylation is a reaction of high importance in the production of a variety of chemicals. Millions of tonnes of aldehydes are produced in this way each year. ${ }^{[1]}$ Hydroformylation of terminal 'alkyl' alkenes shows a preference towards linear aldehyde formation and with the correct ligands near-perfect linear selectivity can be obtained. ${ }^{[1-5]}$ This is used at large scale and in organic synthesis. There are also some very significant chemicals that require a branched-aldehyde selective hydroformylation of a terminal alkene for an efficient synthesis. Sometimes this can be achieved by substrate control. ${ }^{[6,7]}$ However, arguably the most industrially important branched aldehyde is iso-butanal, which requires the very challenging (branched) iso-selective hydroformylation of an unbiased alkyl alkene, propene. ${ }^{[8-10]} \quad$ Global demand for iso-butanal can be estimated to be over half a million tonnes in 2014. ${ }^{[11]}$ Rhodium catalysts derived from ligand $\left(R_{a x}, R, R\right)-1$, (nicknamed BOBPHOS and illustrated in Scheme 2), are extremely unusual in being able to transform simple terminal alkenes into branched aldehydes with good regioselectivity and up to $93 \%$ e.e.; the smallest terminal alkene reported was hex-1-ene. ${ }^{[9]}$ Unfortunately, using either the typical published conditions for operating this catalyst, or the typical temperatures and pressures used in propene hydroformylation, $\mathrm{Rh} / \mathrm{BOBPHOS}$ catalysts do not give satisfactory results in the hydroformylation of propene (see supporting information, Table S1).

The small size of propene renders it less influenced by steric barriers, and possibly reduces attractive interactions as well. A review of the patent and open literature reveals that despite research over decades, iso-selective hydroformylation is very much an unsolved problem, especially at typical reaction temperatures employed in industry. The best selectivity obtained

[a] Dr Leo lu, Dr J. A. Fuentes, Prof. M. L. Clarke EaStCHEM School of Chemistry, University of St Andrews,

Purdie Building, North Haugh, St Andrews, KY16 9ST, United Kingdom

E-mail: mc28@st-andrews.ac.uk

[b] Dr Mesfin E. Janka, Dr Kevin J. Fontenot

Eastman Chemical Company, 200 South Wilcox Drive, Kingsport Tennessee, 37660, USA is $63 \%$ ( $n$ : iso $=0.59$ ); however, this was observed at $19{ }^{\circ} \mathrm{C}$ where rates are not sufficiently high for commodity chemicals production. ${ }^{[10 a]}$ The same catalyst at higher temperatures $\left(80^{\circ} \mathrm{C}\right)$ delivers lower iso selectivity below $50 \% .^{[10 a, d]}$ An alternative benchmark is $57 \%$ (n:iso $=0.75$ ) observed at more typical industrial reaction temperatures (Scheme 1). ${ }^{[8 c, d]}$ Surprisingly, we have now found a combination of reaction conditions and more economic racemic $\mathrm{Rh} /$ phospholane-phosphite catalysts that can deliver unprecedented iso-butanal selectivity from propene and report this discovery here.

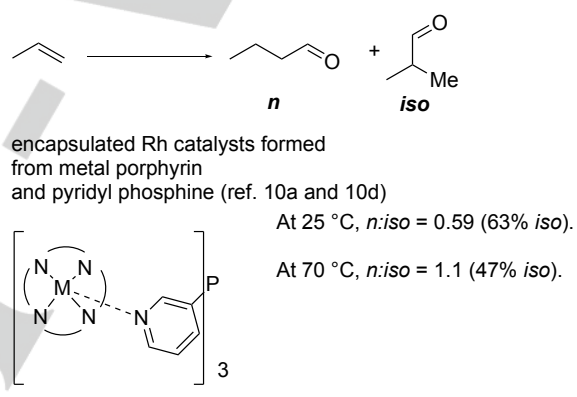

Rh catalyst formed from

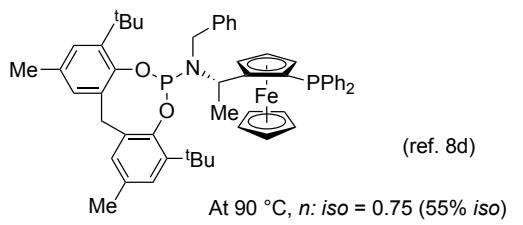

Initial attempts (see ESI) using Rh BOBPHOS or its epimers under standard conditions: $n$ : iso $=0.6-1.2(48-62 \%$ iso $)$.

This work: $n$ : iso down to 0.22 ( $82 \%$ iso)

Selectivity retained with $n$ : iso $\sim 0.3$ at $75^{\circ} \mathrm{C}$

Scheme 1. Iso-selective hydroformylation of propene is highly desired but an extreme challenge.

The unusual regioselectivity observed for Rh catalysts derived from $\left(R_{a x}, R, R\right)-1$ in the hydroformylation of allyl benzene utilises subtle interactions that prevent the linear Rh-alkyl intermediate being formed; an attractive interaction between the phospholane $\mathrm{Ph}$ substituents and the substrate stabilises an unproductive $\mathrm{C}$ $\mathrm{H}$ forming process, on the wrong side of a steric barrier between the transition state and linear Rh-alkyl. ${ }^{[9]]}$ Even subtle changes to the ligand structure might reduce branched selectivity, yet a racemic ligand would be preferable, since it reduces ligand cost very significantly. We speculated that swapping the enantiomerically pure atropos diol for a configurationally unstable tropos diol could deliver a phosphite unit that while interconverting freely as a ligand would set itself in a single preferred conformation upon coordination to rhodium (Scheme 2, 
top). ${ }^{[12]}$ We hoped that this would be an analogous conformation to that observed with $\left(R_{a x}, R, R\right)-1$, rather than its diastereomer, $\left(S_{a x}, R, R\right)-1$, (although this could not be predicted in advance). If the tropos- $R, R$ system were to behave more like $\left(R_{a x}, R, R\right)-1$, it can also be envisaged that utilising a racemic, trans diastereomer of phospholane to partner the tropos diol would lead to two species forming upon coordination that had a similar ligand shape to $\left(S_{a x}, S, S\right)-1$ and $\left(R_{a x}, R, R\right)-1$, but not its diastereomers.

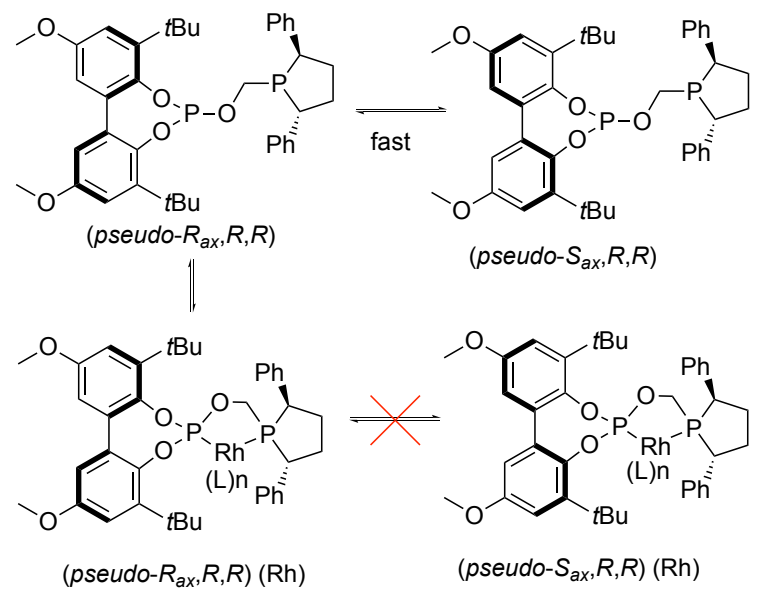<smiles>COc1ccc(O)c(-c2cc(OC)cc(C(C)(C)C)c2OP(OCP2[C@H](c3ccccc3)CC[C@H]2c2ccccc2)Oc2c(OC)cc(OC)cc2C(C)(C)C)c1</smiles>

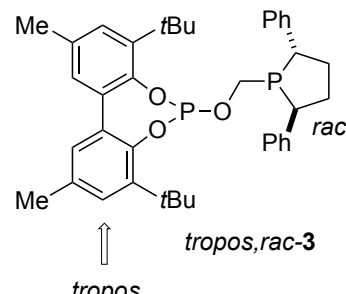

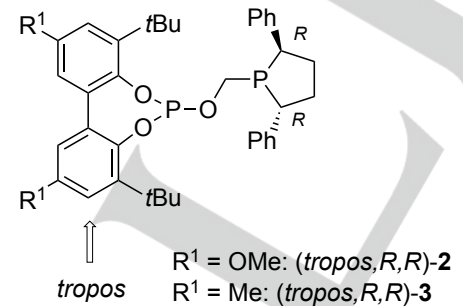

Scheme 2. (top): proposed interconversion of tropos phosphite in free ligands and formation of one atropos isomer on coordination to rhodium; (bottom) ligands used in this study.

In order to test this hypothesis, ligands $\mathbf{2}$ and $\mathbf{3}$ were synthesised (see supporting information). Relative to the parent BOBPHOS ligand, 1 these new derivatives reduce the cost of synthesis as neither the resolution of the racemic phospholane ring, nor the resolution of the diol to produce a single atropisomer is required.

Depending on the borane-protected phospholane used, the $(R, R)$ and tropos, rac analogues of the tropos ligands 2 and $\mathbf{3}$ were synthesised. With the new ligands in hand, a range of variables such as pressure, temperature and solvents were examined. The key finding was the use of the rather unusual

solvent octafluorotoluene, which we previously had observed to offer very marginal gains $(1-3 \%)$ in branched selectivity, ${ }^{[8 d]}$ actually leads to very significantly higher selectivity for this industrially important reaction relative to the state of the art (Table 1). This effect is observed using the new tropos ligands and $\left(R_{a x}, R, R\right)$-BOBPHOS itself. In a variety of studies using these types of catalysts, we have observed that while using $L: R h$ ratios of 1.25:1 can work well, larger $L: R h$ ratios are sometimes needed under certain conditions and a ligand to $\mathrm{Rh}$ ratio of $2: 1$ is recommended here (Table 1 , entries 1 and 2 and supporting information Table S1).

The use of fluorinated solvents has attracted interest for a variety of reasons. ${ }^{[13]}$ Lattanzi et al examined the use of hexafluorobenzene as additive in catalytic asymmetric Michael addition reactions and discovered that only $5-10$ equivalents of hexafluorobenzene relative to the substrates were required to achieve comparable results to those using hexafluorobenzene as the solvent. ${ }^{[13 \mathrm{~d}]}$ The equivalents needed were substratedependent, suggesting the presence of interactions between the substrate and hexafluorobenzene. In this case an experiment using a mixture of toluene and 2205 equivalents of octafluorotoluene w.r.t Rh does not maintain the high selectivity, and hence we believe this is a solvent effect on these reactions (Table 1, Entry 6 and 7).

Commercial production of butanal isomers does not make use of volatile organic solvents, since they would be too expensive; non-volatile solvents that dissolve the catalyst and enable the products to be distilled away, while catalyst and solvent are recycled again and again are preferred. An alternative to the use of volatile octafluorotoluene is therefore likely to be needed for large-scale application. We therefore decided to produce a new solvent that maintains the properties of octafluorotoluene in this reaction, but is no longer volatile.

Pentafluorophenyl $n$-octyl ether (PFPOE), which has never been used as a synthesis solvent before ${ }^{[14]}$ was chosen since it could be made in one step from two simple chemicals and would have a high enough boiling point to not be stripped away from the catalyst. We were delighted to find that using this new solvent, even after increasing reaction temperature to $75^{\circ} \mathrm{C}$, enabled the desired high proportion of iso-butanal, but this time with the improved turnover frequencies (TOF) possible at $75^{\circ} \mathrm{C}$. (Table 1 , entries 12 and 13, and further results in supporting information). We note also that $n$ : iso ratios below 0.5 are possible even at 90 ${ }^{\circ} \mathrm{C}$ in PFPOE (see supporting information). The protio analogue phenyl octyl ether, while giving lower selectivity than the fluorinated variant still enables an impressive iso-butanal yield (see the supporting information).

A promising solution to the long-standing and commercially important problem of obtaining significantly higher proportions of iso-butanal than $n$-butanal in propene hydroformylation is now in place. The new ligands are cheaper to make than the ligand that inspired them, which is also desirable for such relatively low value-high volume commodity chemicals. Both catalyst and solvents will need long term stability to be viable in a commercial process, and these studies and other elements of process development are now underway. 
Table 1. Hydroformylation of propene in fluorinated solvents.

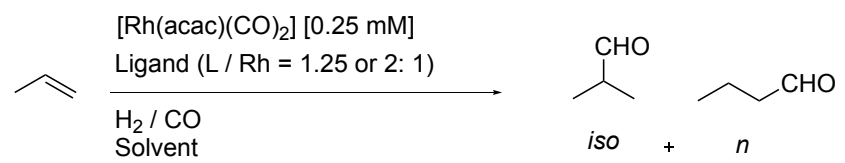

\begin{tabular}{|c|c|c|c|c|c|c|}
\hline Entry $^{[\mathrm{a}]}$ & Ligand & $\begin{array}{l}\mathrm{T} \\
{ }^{\circ} \mathrm{C}\end{array}$ & Solvent & TOF & TON & $\%$ iso \\
\hline 1 & tropos, rac-3 & 50 & $\mathrm{C}_{7} \mathrm{~F}_{8}$ & 42 & 670 & 53.8 \\
\hline $2^{[\mathrm{b}]}$ & tropos, rac-3 & 50 & $\mathrm{C}_{7} \mathrm{~F}_{8}$ & 51 & 820 & $74.2^{[c]}$ \\
\hline 3 & (tropos, R,R)-3 & 50 & $\mathrm{C}_{7} \mathrm{~F}_{8}$ & 42 & 670 & 73.4 \\
\hline 4 & (tropos, $R, R$ )-2 & 50 & $\mathrm{C}_{7} \mathrm{~F}_{8}$ & 37 & 590 & 69.5 \\
\hline 5 & tropos, rac-2 & 50 & $\mathrm{C}_{7} \mathrm{~F}_{8}$ & 36 & 570 & 71.9 \\
\hline 6 & $\left(R_{a x}, R, R\right)-1$ & 50 & $\mathrm{C}_{7} \mathrm{~F}_{8}$ & 49 & 790 & 76.7 \\
\hline 7 & $\left(R_{a x}, R, R\right)-1$ & 50 & $\begin{array}{l}\mathrm{C}_{7} \mathrm{~F}_{8}+ \\
\mathrm{C}_{7} \mathrm{H}_{8} \\
(8: 92)\end{array}$ & 51 & 810 & 56.5 \\
\hline 8 & $\left(R_{a x}, R, R\right)-1$ & 30 & $\mathrm{C}_{7} \mathrm{~F}_{8}$ & 12 & 460 & 82.0 \\
\hline $9^{[\mathrm{b}, \mathrm{d}]}$ & $\left(R_{a x}, R, R\right)-1$ & 75 & $\mathrm{C}_{7} \mathrm{~F}_{8}$ & 350 & 350 & 78.3 \\
\hline $10^{[b, d]}$ & tropos, rac-2 & 75 & $\mathrm{C}_{7} \mathrm{~F}_{8}$ & 340 & 340 & 72.2 \\
\hline $11^{[\mathrm{b}, \mathrm{d}]}$ & tropos, rac-2 & 75 & $\mathrm{C}_{7} \mathrm{~F}_{8}$ & 500 & 500 & 60.3 \\
\hline $12^{[\mathrm{b}, \mathrm{e}]}$ & $\left(R_{a x}, R, R\right)-1$ & 75 & PFPOE & 670 & 670 & 70.3 \\
\hline $13^{[\mathrm{b}, \mathrm{e}]}$ & (tropos, $R, R)-2$ & 75 & PFPOE & 750 & 750 & 67.0 \\
\hline
\end{tabular}

[a] Catalyst preformed from $\left[\mathrm{Rh}(\mathrm{acac})(\mathrm{CO})_{2}\right]\left(5.12 \times 10^{-3} \mathrm{mmol}\right)$ and ligand $\left(6.40 \times 10^{-3}\right.$ or $\left.10.24 \times 10^{-3} \mathrm{mmol}\right)$ by stirring at 8 bar $\mathrm{CO} / \mathrm{H}_{2}$ at reaction temperature for 1 hour in $\mathrm{C}_{7} \mathrm{~F}_{8}(19.35 \mathrm{~mL}+0.65 \mathrm{~mL}$ toluene) prior to running reaction at $50{ }^{\circ} \mathrm{C}$, for 16 hours using propene/CO/ $\mathrm{H}_{2}$ in 1:4.5:4.5 ratio (8 bar initial pressure). Rh concentration $=2.52 \times 10^{-4} \mathrm{~mol} \mathrm{dm}^{-3}$. Product determined by GC using 1-methylnaphthalene as an internal standard. TOF = average TurnOver Frequency in $\mathrm{mol} \mathrm{prod} / \mathrm{mol} \mathrm{cat} / \mathrm{hr}$; TON $=$ TurnOver Number in mol prod $/ \mathrm{mol}$ cat.. [b] Ligand / $\mathrm{Rh}$ ratio of 2:1.[c] i.e. $n$ : iso $=0.35$. [d] Initial Pressure $=18 \mathrm{bar}$, reaction time 1 hour. [e] PFPOE = pentafluorophenyl $n$-octyl ether as solvent, 20 bar, reaction time 1 hour.

It seems likely that our hypothesis regarding the dynamic behaviour of the tropos ligands was at least partially correct. However, to shed light on this, we also studied the enantioselective hydroformylation of allyl benzene using the tropos ligands derived from an $(R, R)$-phospholane (Table 2). It can be seen that the use of the mixture of diastereomers derived from an atropos racemic biphenol leads to no enantioselectivity in these reactions, and much lower iso selectivity (Table 2, entry 1). If the tropos ligands formed two atropisomeric isomers on coordination, similar results to this might be expected. What is observed is a significant contrast; the tropos ligands, (Tropos, $R, R$ )-2 and (Tropos, $R, R)-3$ selectively form one enantiomer with selectivity towards the $R$ enantiomer of 80 to $85 \%$ (Table 2, entries 2-4), not quite matching the results obtained using the desired single enantiomer $\left(R_{a x}, R, R\right)$ BOBPHOS/ Rh catalyst, but clearly showing that at least to a significant extent, the tropos diol is behaving more like a single enantiomer during catalysis. NMR analysis of the catalyst resting state $\left.[\mathrm{Rh}(\mathrm{H})(R, R)-2)(\mathrm{CO})_{2}\right]$ appears to be a single species in agreement with this (see supporting information for NMR spectra).

Table 2. Enantioselective Hydroformylation of allyl benzene and but-1-ene.

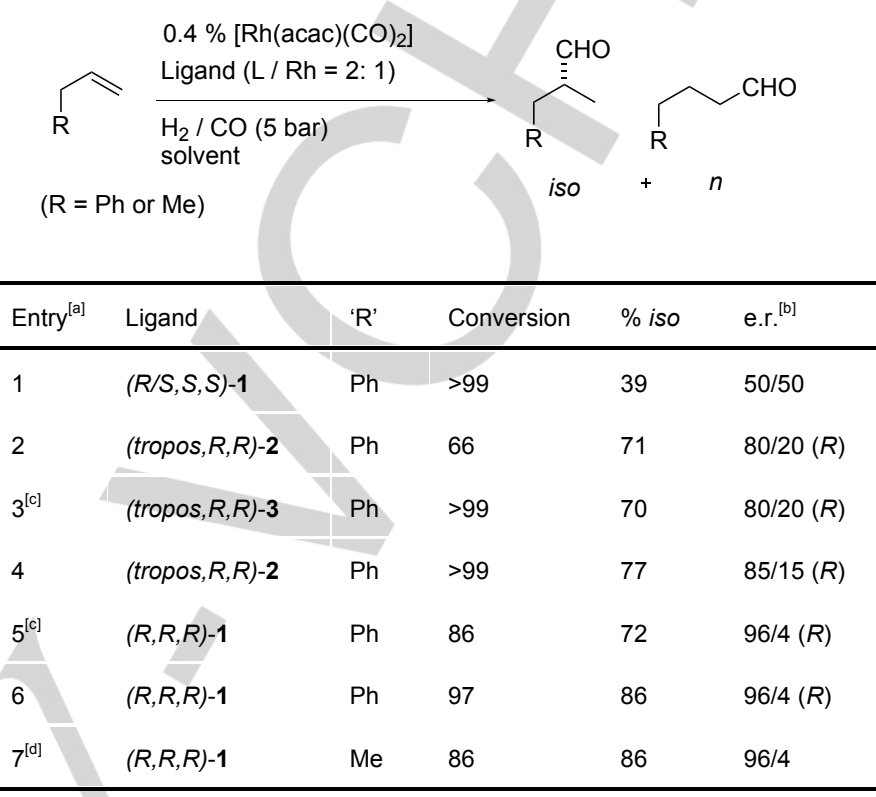

[a] Catalyst preformed from $\left[\mathrm{Rh}(\mathrm{acac})(\mathrm{CO})_{2}\right]\left(4 \times 10^{-3} \mathrm{mmol}\right)$ and ligand $(8 \mathrm{x}$ $10^{-3} \mathrm{mmol}$ ) by stirring at 8 bar $\mathrm{CO} / \mathrm{H}_{2}$ at reaction temperature for 1 hour in octafluorotoluene solvent prior to running reaction at $50{ }^{\circ} \mathrm{C}$, for 16 hours using 5 bar $\mathrm{CO} / \mathrm{H}_{2}$. Conversion and regioselectivity determined by NMR spectroscopy using 1-methylnaphthalene as an internal standard. [b] e.r. determined by HPLC from alcohols obtained after $\mathrm{NaBH}_{4}$ reduction except entry 7). [c] Toluene used as solvent in place of octafluorotoluene. [d] 2.5 bar, $19{ }^{\circ} \mathrm{C}, 64 \mathrm{~h}$; e.r determined by conversion into regiochemically pure $\mathrm{N}$-(4chlorobenzyl)-2-methylbutan-1-amine by reductive amination in $57 \%$ yield from but-1-ene (see supporting information)

An additional aspect discovered here is the higher branched selectivity in asymmetric hydroformylation in octafluorotolene, so these conditions are also a synthetically useful improvement for asymmetric hydroformylation using the Rh / BOBPHOS catalyst. For example highly enantioselective hydroformylation of allyl benzene improved from $72 \%$ regioselectivity to $86 \%$ branched selective under otherwise identical conditions but swapping toluene for octafluorotoluene as solvent (compare Table 2, entries 5 and 6). Unprecedented highly enantioselective and regioselective hydroformylation of but-1-ene was also achieved with $86 \%$ iso-selectivity (Table 2 entry 7 ). The conversion of this aldehyde to a chiral secondary amine with e.r. of 96:4 and isolated as a single regioisomer was also achieved.

In summary we have discovered tropos, racemic ligands that under specific conditions can deliver unprecedentedly high selectivity for iso-butanal in the hydroformylation of propene, with useful rates. The ligands used for this process are more economic to make than the ligand they are inspired from, and hence more suited for development for industrial iso-selective hydroformylation in the future. The fact that the (tropos,rac)ligands/Rh catalysts show comparable results to the $\mathrm{Rh} /$ BOBPHOS catalyst supports the hypothesis that the tropos part 
of the ligand settles into a conformation that is very similar to the single enantiomer BOBPHOS ligands (although it cannot quite be definitively ruled out that one conformation is much more reactive than the other). It may be tempting to speculate about the origin of this effect, but for such a subtle effect, with a critical role for the solvent choice, a definitive answer is outside the reach of DFT calculations or other mechanistic techniques, to our knowledge. Evidently, the reasons for iso-selectivity studied initially for BOBPHOS are either enhanced in the solvents used, or are actually less attenuated than they are by common solvents like toluene, enlarging the scope of substrate that can be used. Finally, the new conditions were also found to improve enantioselective hydroformylation regioselectivity, with highly enantioselective and regioselective hydroformylation of but-1ene exemplifying this improvement.

\section{Acknowledgements}

The authors thank the Eastman Chemical Company for funding (LI, and later JAF) and permission to publish. The EPSRC (EP/M003868/1) is also acknowledged for funding (JAF).

Keywords: Hydroformylation • rhodium • fluorinated solvents • enantioselective catalysis $\bullet$ phosphorus ligands

[1] (a) P. W. N. M. van Leeuwen, in Rhodium Catalyzed Hydroformylation, Vol. 22 (Eds.: P. W. N. M. van Leeuwen, C. Claver), Springer Netherlands, 2002, pp. 1-13; (b) R. Franke, D. Selent, A. Börner, Chem. Rev. 2012, 112, 5675-5732, (c) A. Börner, R. Franke, in Hydroformylation. Fundamentals, Processes, and Applications in Organic Synthesis; Wiley-VCH Verlag GmbH \& Co. KGaA, 2016.

[2] (a) L. Gonsalvi, A. Guerriero, E. Monflier, F. Hapiot, M. Peruzzini, in Hydroformylation for Organic Synthesis, Vol. 342 (Eds.: M. Taddei, A. Mann), Springer Berlin Heidelberg, 2013, pp. 1-47.

[3] (a) T. J. P. Devon, G. W.; Puckette, T. A.; Stavinoha, J. L.; Vanderbilt, J. J. (Eastman Kodak Company), US 4694109 A, 1987; (b) T. J. P. Devon, G. W.; Puckette, T. A.; Stavinoha, J. L.; Vanderbilt, J. J. (Eastman Kodak Company), US 5332846 A, 1994. (c) C. P. Casey, E. L. Paulsen, E. W. Beuttenmueller, B. R. Proft, L. M. Petrovich, B. A. Matter, D. R. Powell, J. Am. Chem. Soc. 1997, 119, 11817-11825; (d) C. P. Casey, E. L. Paulsen, E. W. Beuttenmueller, B. R. Proft, B. A. Matter, D. R. Powell, J. Am. Chem. Soc. 1999, 121, 63-70.

[4] (a) E. Billig, A. G. Abatjoglou, D. R. Bryant, (Union Carbide) EP 213639 , 1987

[5] (a) L. A. van der Veen, M. D. K. Boele, F. R. Bregman, P. C. J. Kamer, P. W. N. M. van Leeuwen, K. Goubitz, J. Fraanje, H. Schenk, C. Bo, J. Am. Chem. Soc. 1998, 120, 11616-11626 and ref's therein

[6] (a) I. Ojima, K. Kato, M. Okabe, T. Fuchikami, J. Am. Chem. Soc. 1987, 109, 7714-7720; (b) C. J. Cobley, K. Gardner, J. Klosin, C. Praquin, C Hill, G. T. Whiteker, A. Zanotti-Gerosa, J. L. Petersen, K. A. Abboud, J. Org. Chem. 2004, 69, 4031-4040; (c) N. Sakai, S. Mano, K. Nozaki, H. Takaya, J. Am. Chem. Soc. 1993, 115, 7033-7034; (d) G. M. Noonan, D. Newton, C. J. Cobley, A. Suárez, A. Pizzano, and M. L. Clarke, Adv. Synth. Catal. 2010, 352, 1047-1054; (e) Z. Yu, M. S. Eno, A. H. Annis, J. P. Morken, Org. Lett. 2015, 17, 3264-3267; (f) F. Shibahara, K. Nozaki, T. Hiyama, J. Am. Chem. Soc. 2003, 125, 8555-8560; (g) X. Wang and S. L. Buchwald, J. Org. Chem. 2013, 78, 3429-3433; (h) B. F. Perandones, C. Godard, and C. Claver, in Hydroformylation for
Organic Synthesis, Vol. 342 (Eds.: M. Taddei, A. Mann), Springer Berlin Heidelberg, 2013, pp. 79-115.

[7] (a) M. Leight Abrams, F. Foarta, C. R. Landis, J. Am. Chem. Soc. 2014, 136, 14583-14588; (b) A. H. Hoveyda, D. A. Evans, G. C. Fu, Chem. Rev. 1993, 93, 1307-1370; (c) C. U. Grünanger, B. Breit, Angew. Chem. Int. Ed. 2008, 47, 7346-7349; (d) A. D. Worthy, C. L. Joe, T. E. Lightburn, K. L. Tan, J. Am. Chem. Soc. 2010, 132, 14757-14759; (e) B. Breit, Acc. Chem. Res. 2003, 36, 264-275; (f) P. Dydio, W. I. Dzik, M. Lutz, B. de Bruin, J. N. H. Reek, Angew. Chem. Int. Ed. 2011, 50, 396400; (g) C. Schmitz, K. Holthusen, W. Leitner, G. Franciò, ACS Catal. 2016, 6, 1584-1589.

[8] (a) R. A. Baber, M. L. Clarke, K. M. Heslop, A. C. Marr, A. G. Orpen, P G. Pringle, A. Ward, D. E. Zambrano-Williams, Dalton Trans. 2005, 1079-1085; (b) E. Zuidema, P. E. Goudriaan, B. H. G. Swennenhuis, P. C. J. Kamer, P. W. N. M. van Leeuwen, M. Lutz, A. L. Spek, Organometallics 2010, 29, 1210-1221; (c) R. C. How, M. L. Clarke, R. T. Hembre, J. A. Ponasik, G. S. Tolleson, (Eastman Chemical Company), US 9308527 B2, 2016; (d) R. C. How, R. Hembre, J. A. Ponasik, G. S. Tolleson, M. L. Clarke, Catal. Sci. Technol., 2016, 6, 118-124; (e) R. C. How, P. Dingwall, R. T. Hembre, J. A. Ponasik, G. S. Tolleson, M. L. Clarke, Molecular Catalysis, 2017, 434, 116-122; (f) A. Phanopoulos and K. Nozaki, ACS Catal. 2018, 8, 5799-5809.

[9] (a) G. M. Noonan, J. A. Fuentes, C. J. Cobley, M. L. Clarke, Angew. Chem., Int. Ed. 2012, 51, 2477-2480; (b) G. M. Noonan, C. J. Cobley. T. Mahoney, M. L. Clarke, Chem. Commun. 2014, 50, 1475-1477; (c) R. Pittaway, J. A. Fuentes, M. L. Clarke, Org. Lett. 2017, 19, 2845-2848; (d) P. Dingwall, J. A. Fuentes, L. Crawford, A. M. Z. Slawin, M. Bühl, M. L. Clarke, J. Am. Chem. Soc. 2017, 139, 15921-15932; (d) (S,S,SBOBPHOS is commercially available from Strem Chemicals.

[10] (a) D. W. Norman, J. N. H. Reek, T. R. M. L. Besset, (Eastman Chemical Company), US 8710275 B2, 2014; (b) n: iso of 0.66 for oct-1ene at higher T:, T. Besset, D. W. Norman, and J. N. H. Reek, Adv. Synth. Catal. 2013, 355, 348-352. c) V. F. Slagt, P. C. J. Kamer, P. W. N. M. van Leeuwen, J. N. H. Reek, J. Am. Chem. Soc. 2004, 126, 1526-1536; d) n:iso of 0.84 at $25{ }^{\circ} \mathrm{C}, 1.1$ at $70{ }^{\circ} \mathrm{C}$ : X. Wang, S. Nurttila, W. I. Czik, R. Becker, J. Rodgers, J. N. H. Reek, Chem. Eur. J. 2017, 23, 14769-14777.

[11] Grand View Research, Mar 2016, Isobutanol Market Analysis By Product (Synthetic, Bio-Based), Application (Oil \& Gas, Solvents \& Coatings, Chemical Intermediates) And Segment Forecasts To 2022, https://www.grandviewresearch.com/industry-analysis/isobutanolmarket

[12] (a) K. Aikawa, K. Mikami, Chem. Commun. 2012, 48, 11050-11069; P. Oczipka, D. Müller, W. Leitner and G. Franciò, Che. Sic. 2016, 7, 678683. G. Storsch and O. Trapp, Angew. Chem. Int. Ed. 2015, 54, 35803586; C. Monti, c. Gennari, U. Piarulli, Chem. Commun. 2005, 52815283; P. W. N. M. van Leeuwen, P. C. J. Kamer, C. Claver, O Pàmies, M. Diéguez, Chem. Rev. 2011, 111, 2077-2118; G. T. Whiteker, A. M. Harrison and A. H. Abatjoglou, Chem. Commun. 1995, 1805-6.

[13] (a) L. C. Clark, F. Gollan, Science 1966, 152, 1755-1756; (b) R. H. Fish, Chem. Eur. J. 1999, 5, 1677-1680; (c) I. Colomer, A. E. R. Chamberlain, M. B. Haughey, T. J. Donohoe, Nature Reviews Chemistry 2017, 1, 0088; (d) A. Lattanzi, C. De Fusco, A. Russo, A. Poaterb, L. Cavallo, Chem. Commun. 2012, 48, 1650-1652; (e) C. Samojłowicz, M. Bieniek, A. Pazio, A. Makal, K. Woźniak, A. Poater, L. Cavallo, J. Wójcik, K. Zdanowski, K. Grela, Chem. Eur. J. 2011, 17, 12981-12993.

[14] D. Prescher, V. E. Platonov, K. V. Dvornikova, J. Schulze, O. I. Osina,G. G. Yakobson, Journal of Fluorine Chemistry, 1985, (29), 204.

[15] The research data supporting this publication can be accessed at https://doi.org/10.17630/6ed96377-ab54-4fb3-98c9-d2a5bc4d333e 
Entry for the Table of Contents (Please choose one layout)

Layout 1:

\section{COMMUNICATION}

Significant selectivity for the branched or iso-aldehydes in the hydroformylation of propene and but-1-ene has been obtained.

Layout 2:

\section{COMMUNICATION}

\section{COMMUNICATION}

Author(s), Corresponding Author(s)*

((Insert TOC Graphic here))
Author(s), Corresponding Author(s)*

Page No. - Page No.

Title

$$
\overbrace{\mathrm{R} \text { iso }}+\Gamma_{\mathrm{R} n}^{\mathrm{CHO}} \begin{aligned}
& \mathrm{R}=\mathrm{H} \text { or } \mathrm{Me} \\
& \text { up to } 86 \% \text { iso }
\end{aligned}
$$

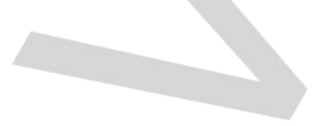

Page No. - Page No.

Title 